\title{
PERIMENSTRUAL AGGRESSION IN GROUPS OF FEMALE RHESUS MONKEYS
}

\author{
ETHEL N. SASSENRATH,* THELMA E. ROWELL† AND \\ A. G. HENDRICKX \\ * Department of Behavioral Biology, University of California School of Medicine, \\ Davis, California 95616, †Department of Zoology, University of California, Berkeley, \\ California 94720, and California Primate Research Center, Davis, \\ California 95616, U.S.A.
}

(Received 23rd October 1972)

The pioneer study of Carpenter (1942) characterized oestrous behaviour in rhesus monkeys by criteria related to increased sexual behaviour and by 'increased aggressiveness ... and wounds'. Subsequent studies of rhesus monkeys by Bernstein (1963) and Lindburg (1971) have confirmed a mid-cycle increase in behavioural arousal which appears to coincide with ovulation (as judged from subsequent pregnancy data). Loy (1970) now reports an increase in socalled 'estrous behavior' both perimenstrually and at mid-cycle in freeranging rhesus monkeys. Rowell (1963) has observed increased perimenstrual aggressive interaction, but differentiates increased aggression received during the premenstrual week from increased aggression exerted on cage mates during the week after the onset of menstruation.

The present study is an attempt to relate bite wounds and menstrual cycle data for groups of rhesus, Macaca mulatta, females maintained in groups caged in the breeding colony of the California Primate Research Center. This is a retrospective analysis of routine laboratory records over the 16-month period from July 1967 to November 1968, representing 2638 'female months', i.e. 6 months' records for thirty-six cages with an average monthly total population of $208 \pm 15$ (S.D.) plus an additional 10 months' records for eighteen of these cages with an average monthly total population of $123 \pm 10$. Each female was inspected daily for signs of menstruation (blood in vulva), fresh bite wounds, and illness. At the time of observation, only menstruation data were utilized for breeding purposes.

In the course of these records, a total of 130 bite wounds was recorded, apparently resulting from the most severe aggressive encounters occurring under the conditions of relatively high crowding stress in the caged group. Bite wounds represent a rather constant proportion of total agonistic interaction in a social group (T.E. Rowell, unpublished observations) and thus can serve as a crude indicator of behavioural changes. The wounds recorded here appeared to occur randomly with no evidence of clustering relative to cage location or time of occurrence. Of the total bite wounds, ninety-three (for seventy-four females) could be related to the preceding and/or subsequent onset of menstruation for that female, as shown in Text-fig. $1(a)$ and (b). The balance of the wounds not 
plotted here occurred during apparently amenorrhoeic periods, near the time of transfer to or from other caging where daily inspection was not made, or before removal from group caging because of pregnancy or illness. For these same reasons, not all of the ninety-three wounds could be plotted relative to both prior and subsequent onset of menstruation, so that Text-fig. 1 contains two separate plots: (a) showing the percentage distribution of forty-three wounds occurring before the onset of menstruation and (b) showing the distribution of seventy-two wounds occurring after the onset of menstruation. Both plots show corroborating distributions, with significantly elevated frequencies just before menstruation (Text-fig. 1a) and just after the onset of the menses (Text-fig. 1b), low frequencies of wounds at mid-cycle, and a suggestion of a secondary peak around \pm 25 to 30 days, i.e. near the time of previous or subsequent menstruation.
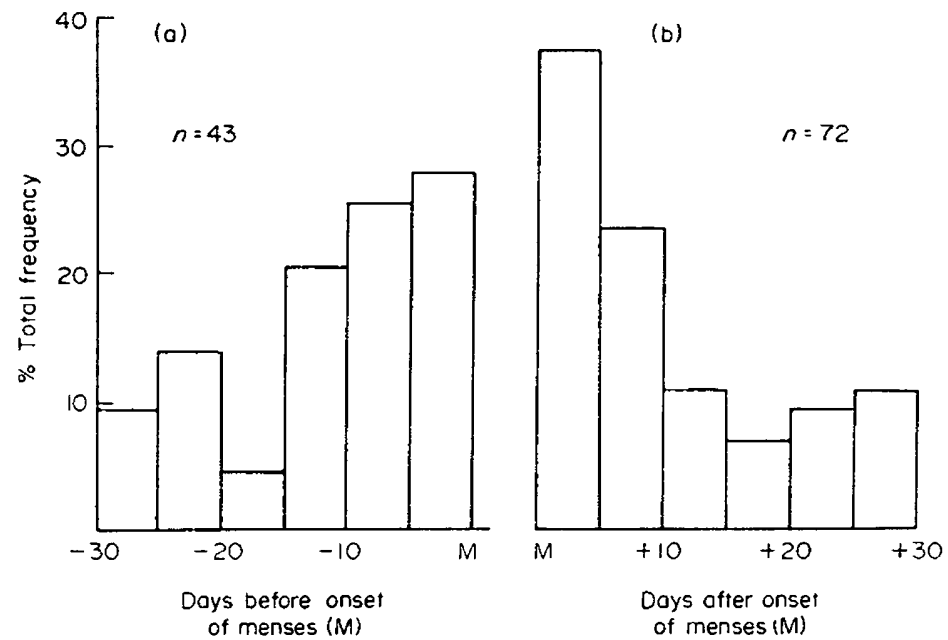

TEXT-FIG. 1. Frequency percentage distribution of bite wounds in caged groups of female rhesus monkeys plotted in relation to the preceding or succeeding onset of menstruation.

In the total sample, bite wounds occurred significantly more frequently in the first 5 days of the cycle $\left(\chi^{2}\right.$ gives $\left.P<0.001\right)$. Wounding at this time did not appear to be correlated with observable menses: during the 10-day interval after onset of the menses, $70 \%$ of menses terminated by Day +4 , and only $38 \%$ of wounds occurred in this 4-day period. Premenstrual data also suggest a significant but less pronounced increase in wounding during the 5 days before menstruation $(P<0 \cdot 10)$. If the 7 days before menstruation is compared with the rest of the cycle, the increase in wounding is significant at the $P<0.001$ level.

These findings for caged groups of rhesus monkeys differ from those of Rowell (1963) in that the initiator of the aggression is not identified. The possibility that females which inflicted wounds may have been cycling in parallel with the wound recipients was considered, but no evidence could be found for synchronous menstrual cycles in any of the cage records from which the present data were drawn. Rowell (1970) has noted that attacks on female baboons in a cage group were also most frequent around menstruation. 
It appears likely that the determinant of perimenstrual fighting, as judged here by incidence of bite wounds, is a function of the recipient of the wounds. This increased fighting may be mediated through a direct pheromonal effect or a perimenstrual change in behavioural affect similar to the increase in negative affect in women (Gottschalk, Kaylan, Gleser \& Winget, 1962; Ivey \& Bradwick, 1968; Paige, 1971). Since there is clearly no mid-cycle peak in wounding, this phenomenon appears to differentiate the general behavioural arousal which is observed around menstruation from that which is coincident with ovulation.

\section{REFERENCES}

Bernstein, I. S. (1963) Social activities related to rhesus monkey consort behavior. Psychol. Rep. 13, 375.

GARPENTER, G. R. (1942) Sexual behavior of free ranging rhesus monkeys (Macaca mulatta): specimens, procedures and behavior characteristics. F. comp. Psychol. 33, 113.

Gottschalx, L., Kaylan, S. M., Gleser, G. G. \& Winget, C. M. (1962) Variations in magnitude of emotion: a method applied to anxiety and hostility during phases of the menstrual cycle. Psychosom. Med. 24, 300.

Ivey, M. E. \& Bradwick, J. M. (1968) Patterns of affective fluctuation in the menstrual cycle. Psychosom. Med. 30, 336.

LindBuRG, D. G. (1971) The rhesus monkey of North India: an ecological and behavioral study. In: Primate Behavior: Developments in Field and Laboratory Research, Vol. 2. Ed. L. A. Rosenblum. Academic Press, New York.

Loy, J. (1970) Perimenstrual sexual behavior among rhesus monkeys. Folia Primatol. 13, 286.

PAige, K. (1971) Effects of oral contraceptives on affective fluctuations associated with the menstrual cycle. Psychosom. Med. 33, 515.

Rowels, T. E. (1963) Behaviour and female reproductive cycles of rhesus macaques. F. Reprod. Fert. $6,193$.

Rowelt, T. E. (1970) Baboon menstrual cycle affected by social environment. F. Reprod. Fert. 21, 133. 